\title{
Optimización de un protocolo de cultivo in vitro de embriones de Coyol (Acrocomia aculeata)
}

\section{Optimization of an in vitro culture protocol of Coyol embryos (Acrocomia aculeata)}

Katherine Sánchez-Zúñiga ${ }^{1}$, Elizabeth Arnáez-Serrano², Ileana Moreira-González ${ }^{3}$, Guillermo Vargas-Hernández ${ }^{4}$

Sánchez-Zúñiga, K; Arnaéz-Serrano, E; Moreira-González, I; Vargas-Hernández, G. Optimización de un protocolo de cultivo in vitro de embriones de Coyol (Acrocomia aculeata). Tecnología en Marcha. Especial 2019. 25 Aniversario del Centro de Investigación en Biotecnología. Pág 30-35.

doi) https://doi.org/10.18845/tm.v32i9.4624

1 Ingeniera en Biotecnología. Escuela de Biología Instituto Tecnológico de Costa Rica. Costa Rica. Correo electrónico: katsanchez@tec.ac.cr (iD) https://orcid.org/0000-0003-3615-2041

2 Bióloga. Escuela de Biología. Instituto Tecnológico de Costa Rica. Costa Rica. Correo electrónico: earnaez@tec.ac.cr (iD) https://orcid.org/0000-0003-4058-4429

3 Bióloga. Escuela de Biología. Instituto Tecnológico de Costa Rica. Costa Rica.Correo electrónico: ilea2757@gmail.com 


\section{Palabras clave}

Acrocomia aculeata; coyol; cultivo in vitro de embriones de coyol; bioenergía.

\section{Resumen}

El coyol (Acrocomia aculeata), es una palma distribuida principalmente en la Región del Pacífico de Costa Rica, su principal uso ha sido la obtención de una bebida conocida como vino de coyol y los frutos como alimento para el ganado. Además, es una especie que tiene un gran potencial, debido a que de los frutos y semillas se puede obtener aceite que puede ser utilizado para producir biodiesel, alimentos y cosméticos, entre otros.

Son pocas las plantaciones comerciales que existen en el mundo, sin embargo, Brasil es uno de los países que está apostando a la siembra de esta especie en mayores extensiones. Uno de los problemas que se tiene al trabajar con esta especie es la alta dormancia de sus semillas y los bajos porcentajes de germinación. Por tal motivo el objetivo del trabajo fue el establecimiento y estandarización de un protocolo de germinación in vitro de embriones de coyol (A. aculeata).

Se colectaron frutos de plantas de coyol (A.aculeata) ubicadas en diferentes sitios de las provincias de Guanacaste, Alajuela, San José y Puntarenas de Costa Rica, durante el año 2018. Se separó el exocarpo y mesocarpo y se desinfectó el endocarpo, posteriormente se extrajeron los embriones y se sembraron en diferentes medios de cultivo in vitro. Se logró obtener un protocolo de desinfección y de germinación.

\section{Keywords}

Acrocomia aculeata; coyol; in vitro culture of coyol embryos; bioenergy.

\section{Abstract}

Coyol (Acrocomia aculeata), is a palm distributed mainly in the Pacific Region of Costa Rica, its main use has been to obtain a drink known as coyol wine and the fruits as feed for livestock. In addition, it is a species that has great potential, because of the fruits and seeds you can obtain oil that can be used to produce biodiesel, food and cosmetics, among others.

There are few commercial plantations that exist in the world, however Brazil is one of the countries that is betting on planting this species in larger areas. One of the problems we have when working with this species is the high dormancy of its seeds and the low percentages of germination. For this reason, the objective of the work was the establishment and standardization of an in vitro germination protocol of coyol embryos ( $A$. aculeata).

Fruits were collected from coyol plants (A. acuelata) located in different sites in the provinces of Guanacaste, Alajuela, San José and Puntarenas of Costa Rica, during 2018. The exocarp and mesocarp were separated and the endocarp was disinfected, subsequently embryos were extracted and seeded in different in vitro culture media. A disinfection and germination protocol was obtained.

\section{Introducción}

Acrocomia aculeata pertenece a la familia Arecaceae, que está ampliamente dispersa por todo América [1] . Entre las palmas oleaginosas, el coyol es la segunda productora de aceite (1500 - 5000 kg ha-1), alcanza el pico de producción después de los 4 años y puede producir por más de 100 años, estos atributos le confieren al coyol un gran potencial para la producción de biodiesel [2]. 
Puede alcanzar hasta los 10 metros de altura, presenta un tronco simple, cubierto de numerosas espinas oscuras. Las hojas son pinnadas, alternas, de 2-3 metros de largo, con apariencia plumosa, tienen segmentos estrechos que salen del raquis en 4 direcciones diferentes [3]. Presenta una inflorescencia en forma de panícula de gran tamaño, aparecen en medio de las hojas, con una espata espinosa de hasta $1 \mathrm{~m}$ de largo. Los frutos son esféricos, pueden medir hasta $3 \mathrm{~cm}$ de diámetro y contienen una semilla por fruto [4].

Las plantaciones comerciales a nivel mundial son muy reducidas [5], esta situación está muy relacionada con los problemas de propagación que presenta la especie, las semillas son ortodoxas, presentan una alta dormancia y muy bajos porcentajes de germinación [1]. De los frutos se obtiene aceite y se produce biodiesel [3]. El aceite presenta un alto valor alimenticio, además también se pueden obtener otros productos derivados como harina comestible, forraje y combustible de alto valor calorífico [6]. En Costa Rica además de usarse como bebida, los frutos son mayormente utilizados como alimento para el ganado, siendo esta una fuente de alimentación natural para los animales en pastoreo. Aparte de esto, se es conocido que su savia fermentada puede ser utilizada para hacer el llamado vino de coyol, un tipo de licor común en la zona de Guanacaste. Entre los usos rurales que se le han atribuido a la planta se destacan el uso de sus hojas para poner adentro de estructuras destinadas a la maduración de plátano para evitar que animales como los murciélagos entren [7].

Los procesos de germinación de las semillas en las plantas de la familia Arecaceae pueden verse afectados por factores como la temperatura, el substrato y el estado de maduración de los frutos [3]. La maduración del fruto se puede evaluar mediante la coloración del exocarpo, se han observado mayores porcentajes de germinación cuando los frutos están en estadios más avanzados. Otra característica importante en esta familia está relacionada con los mecanismos de dormancia de las semillas, provocando que la germinación ocurra de forma muy lenta [5]. La hidratación del embrión es esencial para desencadenar los procesos de germinación del mismo. Sin embargo, también se presentan otras barreras físicas que impiden el desarrollo embrionario, como la existencia de un endocarpo pétreo que afecta la emergencia de las plántulas [8].

Para la conservación de la diversidad de los recursos genéticos es necesario el empleo de técnicas biotecnológicas, como lo es el cultivo de tejidos, que permite la reproducción de las plantas de forma más rápida y efectiva [5]. En el caso específico del coyol (A.aculeata), el cultivo in vitro de embriones permite disminuir los tiempos de germinación de la semilla y aumentar la tasa de germinación mediante el control de las condiciones de laboratorio [3]. Uno de los factores que contribuyen a la maduración de los frutos es la aplicación de reguladores de crecimiento [9].

El objetivo del trabajo fue el establecimiento y estandarización de un protocolo de germinación in vitro de embriones de coyol (A. aculeata).

\section{Metodología}

Lugar de estudio y obtención del material vegetal

Los ensayos se realizaron en el Centro de Investigación en Biotecnología (CIB) del Instituto Tecnológico de Costa Rica, ubicado en Cartago, Costa Rica a 1360 msnm. Los frutos fueron colectados de racimos maduros de plantas de coyol (A.aculeata) ubicadas en diferentes sitios de Guanacaste (Abangares, Tilarán, Cañas y Limonal), Alajuela (Atenas y Orotina), San José (Puriscal y Turrubares) y Puntarenas (Chomes y Sardinal). (Licencia de colecta científica/ Académica SINAC-SE-0157-2017. Ministerio de Ambiente y Energía. Costa Rica). 


\section{Desinfección y germinación in vitro de embriones}

Se secaron los frutos al sol para facilitar la separación del exocarpo - mesocarpo, esto se realizó de forma mecánica, posteriormente en el laboratorio se desinfectó el endocarpo, este se mantuvo en agitación con agua destilada con 5 gotas de tween 20 durante 10 minutos, se hizo un lavado con agua estéril y se preparó una solución de bactericida - fungicida (3 g/L) y se mantuvieron en agitación durante 15 minutos, se realizaron tres lavados con agua destilada estéril. Se sumergieron en una solución de hipoclorito de sodio al 3,5\% i.a. y se conservaron en agitación durante 25 minutos, luego fueron colocados en una cámara de flujo laminar y se realizaron tres lavados con agua destilada estéril, se dejaron 10 minutos en alcohol de 95\%, nuevamente se realizaron tres lavados con agua destilada estéril y se procedió a romper el endocarpo para extraer el embrión.

Los embriones se sembraron en un medio de cultivo semi-sólido (Tratamiento 1) con sales y vitaminas M\&S al 100\%, suplementado con ácido cítrico (3mg/L), cisteína (3mg/L), ácido giberélico $(1 \mathrm{mg} / \mathrm{L})$, sacarosa $(30 \mathrm{~g} / \mathrm{L})$ y gelificante. También se utilizó un medio control (Tratamiento 2) M\&S al $100 \%$ sin reguladores y sin suplementos. Los embriones se colocaron en un cuarto de crecimiento a $26^{\circ} \mathrm{C}$ y se mantuvieron en oscuridad durante dos semanas, posteriormente se expusieron a la luz y se realizaron subcultivos cada cuatro semanas.

Se realizó la prueba $Q$ de Cochran para encontrar las diferencias estadísticas entre los tratamientos, el estadístico Q de Cochran sigue una distribución de Ji-cuadrado con K-1 grados de libertad y un $\alpha$ de $p \leq 0.05$.

\section{Resultados y Discusión}

\section{Germinación in vitro de embriones}

La germinación de los embriones se observó a las 4 semanas de cultivados (Fig. 1), en esta etapa se evaluó la oxidación de los mismos y se subcultivaron en medio nuevo. Se alcanzaron tasas de germinación del 47\% aproximadamente con el T1 y del 33\% con el T2. En cuanto a los porcentajes de contaminación se tiene una tasa del 10\% con ambos tratamientos. Aproximadamente entre las 8 y 10 semanas aparecen los cotiledones y algunas plántulas empiezan la formación de raíces adventicias muy pequeñas. Se encontraron diferencias significativas entre el tratamiento $\mathrm{T} 1$ y el control sin reguladores de crecimiento (T2), según la prueba $Q$ de Cochran con un $\alpha$ de $p \leq 0.05$, por lo tanto, de acuerdo con los porcentajes de germinación obtenidos se observó que los embriones presentaron un mayor desarrollo en el medio suplementado con reguladores de crecimiento (Fig.1). La mayoría de los embriones que no germinaban, provenían de frutos que fueron colectados del suelo y que tenían un exocarpo muy seco o el endocarpo expuesto, por lo que se procedió a utilizar únicamente embriones de frutos que aún estaban en el racimo. En este caso se notó que la germinación depende de la adecuada madurez del fruto.

Resultados similares fueron reportados por Angulo et al (2006) [10] y otros autores [11]; [12] en donde la utilización de reguladores de crecimiento no influye en la germinación de los embriones, sin embargo, la aplicación de compuestos antioxidantes combinado con la ausencia de luz durante al menos 20 días, sí presenta un efecto significativo en la reducción de la oxidación y por ende el aumento en la viabilidad de los embriones. Dias et al (2013) [13] también resaltan que el uso de ácido giberélico en el medio de cultivo no presenta diferencias significativas con respecto a la germinación de los embriones aislados, sin embargo, sí tiene influencia en el desarrollo del embrión cuando se siembra la semilla completa con el opérculo [13]. La utilización de antioxidantes en el medio de cultivo se basa en el principio de que estos 
compuestos son donadores de electrones, con lo cual inhiben la oxidación de sustratos porque pueden remover oxígeno de otras moléculas. La oxidación de los compuestos fenólicos en cultivo de tejidos son catalizados por la enzima polifenol oxidasa, la cual produce quinonas. En la mayoría de los casos los compuestos fenólicos son exudados por la herida del tejido hacia el medio o por la acción de la activación de algunas rutas metabólicas como la del ciclo sikimico, esto puede reducirse o evitarse cuando se mantienen los embriones en condiciones de oscuridad [14]; [11]. Una vez exudados los compuestos fenólicos, quedan atrapados en el medio, acumulándose alrededor del explante, causando la inhibición del crecimiento y la necrosis. Con respecto a los problemas causados por la liberación de fenoles, existen una serie de compuestos utilizados en el cultivo de tejidos como antioxidantes, de los que mayormente se agregan al medio y que a la vez presentan los mejores resultados resalta el carbón activado, L-cisteína y el ácido citríco [14]. La combinación de antioxidantes utilizada en el medio T1 permitió controlar completamente la oxidación. La adición de ácido giberélico al medio T1 se dio por cuanto las giberelinas regulan los procesos de crecimiento y desarrollo de las semillas. Naturalmente las giberelinas se sintetizan en los tallos jóvenes y propiamente en las semillas, por lo que se promueve aumentar la concentración de estas sustancias para acortar los tiempos de dormancia de las semillas [15]. Naturalmente las semillas de A. aculeata pueden presentar largos períodos de dormancia aproximadamente entre 5-10 años (se consideran como ortodoxas), esta limitante dificulta el establecimiento comercial del mismo, de tal forma que la aplicación de técnicas biotecnológicas como el cultivo de tejidos contribuyó a disminuir significativamente la latencia de las semillas [8]; [16]. Mediante el cultivo in vitro de embriones se logró obtener una germinación en aproximadamente 56 días, las plántulas aún se encuentran en fase de laboratorio, falta estandarizar el medio de cultivo de enraizamiento para proceder a la fase de aclimatación.

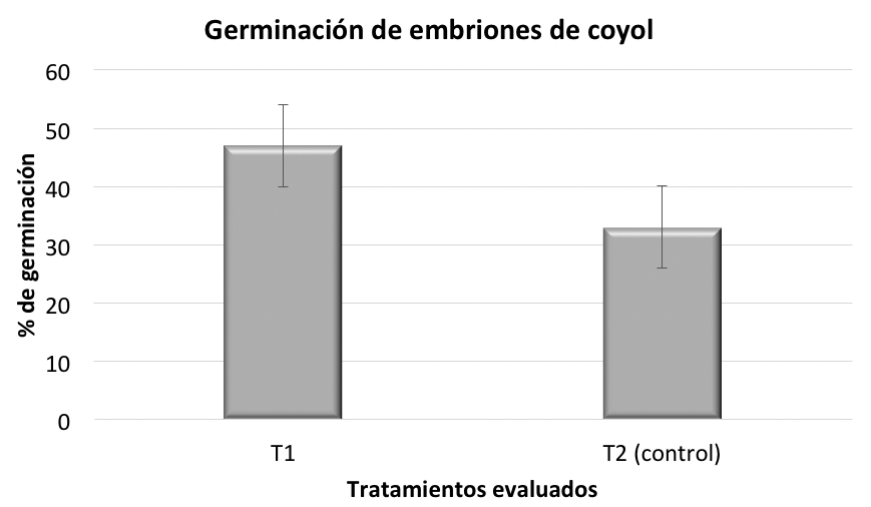

Figura 1. Porcentaje de germinación de los embriones de coyol (Acrocomía aculeata) en dos medios diferentes. T1: M\&S al 100\% suplementado con ácido giberélico, antioxidantes y vitaminas M\&S. T2: M\&S al 100\% con vitaminas M\&S.

\section{Conclusiones}

La técnica de cultivo in vitro aceleró el proceso de germinación de los embriones. Además, el protocolo de desinfección permitió el establecimiento de las semillas en un 100\%. Aproximadamente entre las 8 - 10 semanas se observó la aparición de cotiledones, por otro lado, la adición de ácido giberélico al medio de cultivo aumentó el porcentaje de germinación, obteniéndose un $47 \%$ se semillas germinadas con el medio T1. 
Se encontraron diferencias estadísticas en cuanto al tratamiento suplementado con reguladores de crecimiento (T1) y el tratamiento control (T2) según la prueba $Q$ de Cochran con un $\alpha$ de $p$ $\leq$ 0.05. Se observó que los embriones presentaron un mejor desarrollo en el medio T1, por lo tanto, la adición de regulares de crecimiento tiene una influencia positiva en la germinación y el desarrollo de los mismos.

La aplicación de antioxidantes en el medio de cultivo junto con la ausencia de luz durante un período de al menos 4 semanas, presentó un efecto significativo en la reducción de la oxidación y por ende se produjo un mayor aumento en la viabilidad de los embriones. También se realizaron subcultivos periódicos para renovar el medio y reducir la necrosis ocasionada por la oxidación.

\section{Referencias}

[1] C. B. Sorol, D. I. Haupenthal y M. E. Reckziegel, «Caracterizacion de la germinacion, la plantula y el crecimiento incial de Acrocomia aculeata (Jacq.) ex Mart,» Rojasiana, vol. 11, 2012.

[2] E. Ferreira, M. Contin y S. Yoshimitsu, «Anatomy, histochemistry and ultrastructure of seed and somatic embryo of Acrocomia aculeata,» Scientia Agricola, vol. 67, n 4, 2010.

[3] A. Rubio Neto, F. Guimarañes Silva, J. De Fatima Sales, L. Leandro Pires, B. Silva Morais de Freitas y A. Lorrayne Souza, «Effects of drying temperature on viability of macaw palm (Acrocomia aculeata) zygotic embryos,» African Journal of Biotechnology, vol. 14, n 4, 2015.

[4] N. Zamora, J. González y L. Poveda, Árboles y arbustos del bosque seco de Costa Rica, San Jóse, Costa Rica: Instituto Nacional de Biodiversidad, 1999.

[5] A. Velazquez Mendez, «Caracterizacion Fitoquimica, molecular y evaluacion de respuestas del cultivo in vitro de coyol (Acronomia mexicana Kraw ex Marti), » Chapingo, Mexico, 2013.

[6] M. Díaz, R. Navarro y F. Ruíz, «Morfoanatomía de embriones de Acrocomia aculeata Lodd. ex. Mart.,» Chapingo Ciencias Forestales y del Ambiente, vol. 24, n 1, pp. 91 - 100, 2018.

[7] A. Masis, R. Espinoza, D. Perez, F. Chavarria y A. Guadamuz, «Area de Conservacion Guanacaste,» 1998. [En línea]. Available: https://www.acguanacaste.ac.cr/paginas_especie/magnoliophyta/arecaceae/acrocomia_aculeata/a_aculeata30jun98/a_aculeatas30jun98.html. [Último acceso: 7 Marzo 2019].

[8] A. Rubio, F. Guimaraes, J. de Fatima, E. Fialho, L. Queiroz y R. Candido, «Dormancy breaking in macaw palm (Acrocomia aculeata) seeds, Acta Scientiarum Agronomy, vol. 36, n 1, pp. 43 - 50, 2014.

[9] M. Viñas y V. Jiménez, «Factores que influyen en la embriogenésis somática in vitro de palmas (Arecaceae), » Colombiana de Biotecnología, vol. 13, n 1, pp. 229 - 242, 2011.

[10] V. Ángulo Gonzalez, R. Vázquez Ortega, F. Gutiérrez Miceli y T. Ayora Talavera, Escritores, Germinación in vitro de embriones cigóticos inmaduros de coyol (Acrocomia mexicana KART. EX MART). [Performance]. IV Congreso Internacional de Ingeniería Bioquímica, 2006.

[11] C. Fiori Fernández, M. Díaz Lezcano y L. González Segnana, «Enraizamiento in vitro de embriones cigóticos de Acrocomia aculeata (Jacq.) Lodd ex Mart., Colombia Forestal, vol. 19, n 1, pp. 67 - 78, 2015.

[12] L. Monteiro Ribeiro, D. Trombert Oliveira y Q. de Souza Garcia, «Structural evaluation of zygotic embrios and seedlings of the macaw palm (Acrocomia aculeata, Arecaceae) during in vitro germination, 》rees, vol. 26, pp. 851-863, 2012.

[13] D. Dias, P. Lopes, L. Ribeiro, L. Oliveira, E. Mendes y V. Carvalho, «Effects of seed structures, sucrose and gibberellic acid on the germination of Butia capitata (Arecaceae), » Seed Science and Technology, vol. 41, $\mathrm{n}^{\circ}$ 3, pp. 371 - 382, 2013.

[14] R. Ancansi Espejo, J. Montero Tonconi, N. Ferreira Castedo y I. Munoz Guzmán, «Determinación de un mejor medio de cultivo en la fase de establecimiento para la propagación in vitro de plátano (Musa paradisiaca L), » Journal of the Selva Andina Research Society, vol. 7, n 2, 2016.

[15] M. Jordán y J. Casarretto, «Hormonas y reguladores de crecimiento: auxinas, giberelinas y citocininas, Fisiología Vegetal, pp. 806 - 834, 2006.

[16] A. Goncalves, T. Soares, P. Pereira y L. Monteiro, «Water uptake and pre-germination treatments in macaw palm (Acrocomia aculeata - Arecaceae) seeds, » Journal of seed Science, vol. 35, n 1, 2013. 